\title{
Structurally-Oriented Design of the Heat Insulation Plastering Material
}

\author{
Vladimir Kersh ${ }^{1}$, Andrey Kolesnikov ${ }^{2}$, Tatyana Lyashenko ${ }^{3}$, Maria Pidkapka ${ }^{4}$, \\ ${ }^{1-4}$ Odessa State Academy of Civil Engineering and Architecture
}

\begin{abstract}
Theoretical foundations and the results of preliminary experimental studies related to the design of the heat insulation plastering material are considered. The main problem is to provide heat-insulating properties and strength characteristics of the appropriate level required. The solution is based on the percolation theory, allowing to determine the proportion of thermal insulating filler to interrupt most of thermal paths, and ideas of structural optimization, allowing to increase the strength of the material due to the selection of particle size of the basic components - gypsum and perlite powder, as well as by the introduction of mineral and organic additives. Methodological techniques developed in the implementation of these directions are applicable for other tasks of building materials science.
\end{abstract}

Keywords - Heat insulation, plastering, percolation, structure, optimization, regression models

One of the main tasks of building materials, especially topical for Ukraine, is to create multi-functional energy-saving materials for different purposes and in particular for insulating plastering compositions. Characteristic features of the materials considered are almost opposing the requirements and restrictions on properties: strength $\mathrm{Rpr}$ more $1 \mathrm{MPa}$, the adhesive activity of at least $0.8 \mathrm{MPa}$, the sound insulating ability combined with low density, thermal conductivity less than $0.1 \mathrm{~W} /(\mathrm{mK})$, and cheapness. It is necessary to apply specific techniques and methods to meet these requirements. The problem of optimal design of the material is solved by creation of a sequence of theoretical and experimental models, each of which specifies the previous and includes consideration of more specific material properties.

Gypsum was selected as the initial binder and perlite powder - as the main heat-insulating filler. Microspheres, metakaolin, limestone, silica fume, styrene-acrylic latex were considered as the additives which modify the structure of the material. The ratio of the main components was chosen based on the percolation theory.

The method of electro-thermal analogy, according to which we establish the relations "conductor-insulator", in which the electrical conductivity changes abruptly - there is percolation conductivity jump, was used in preliminary model experiments. (Fig. 1)

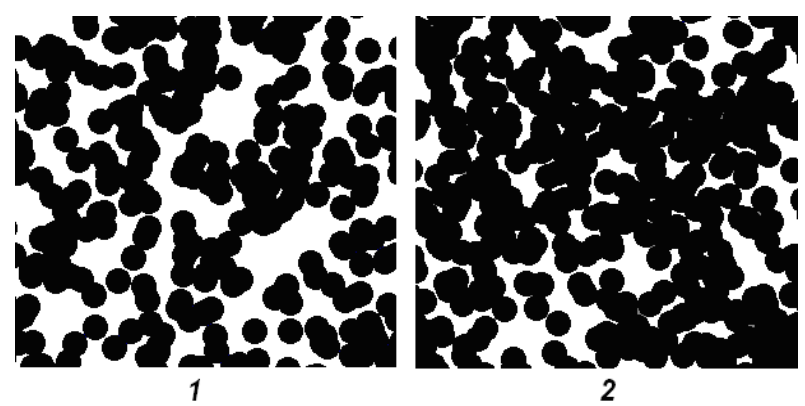

Fig. 1. Percolation conductivity jump.

1- the concentration of insulating particles (dark) in conductive media (light) low, flow conditions are performed, the mixture has high electrical conductivity; 2 - the concentration of the insulating particles is high, flow does not occur, the mixture conductivity is low.

The insulator fillers and additives with their individual properties of the particles used for further study fillers were tested, the fine carbon powder modeling solid environment served as conductor.

Study of the nature of dependence of the conductivity on the volume fraction of the input isolator allowed determining the value of the percolation threshold, which for the materials considered amounted to $80-85$ volume percent of the insulating component (Fig.2), that approximately corresponds to the values predicted by the percolation theory [1], [2].

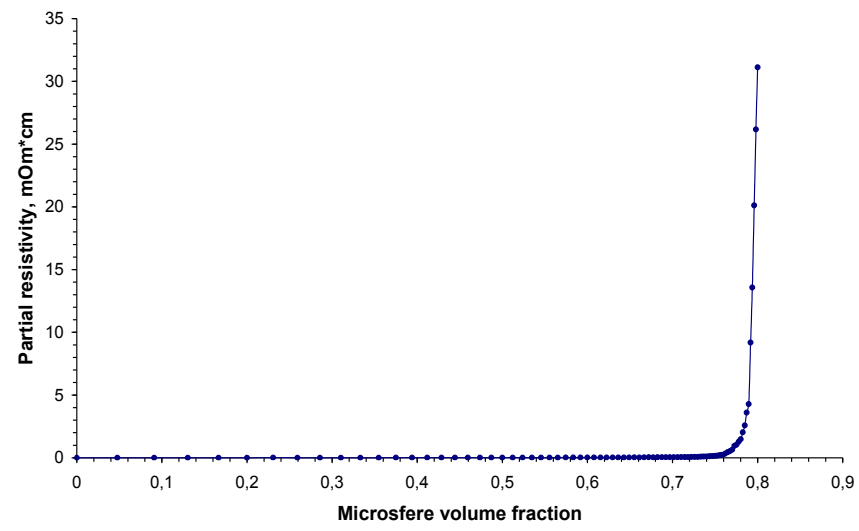

Fig.2. The observed percolation jump for the system modeling the materials in question. 
The study of dry mixtures - models of the materials - has shown that for the thermal conductivity such a jump is not typical, and instead there is a smooth transition in the region of percolation, which is explained by comparable values of thermal conductivity of the examined components. However, the specified percolation transition can be used for the optimization of composition and properties of the material.

As far as in the percolation theory the uniform distribution of particles and connections are considered, it was used as the first approximation. More accurate consideration required the account of orderly grouping of particles and structures of formed groups (clusters). A pivotal role is played by the concept of the structural completeness and stability of the clusters. They are universal and are applicable as a model system and to the studied composite mixture.

The structural completeness is a quantitative characterization of clusters having also a qualitative agreement. A simplified method of its introduction is based on the consideration of "reactions" of the kind presented in Fig.3:

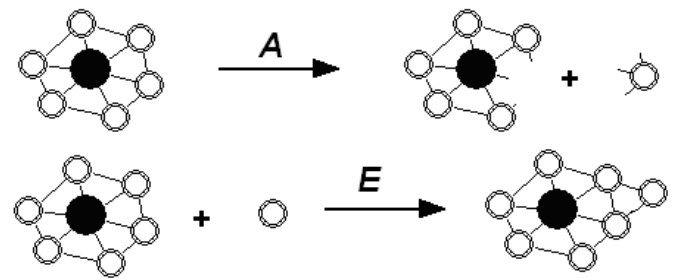

Fig. 3. Transformations of the clusters of particles of the material. Explanations in the text.

The process of destruction of the cluster by cleaving one particle of the inert material (filler and mineral additives), for which you have to perform the work $\mathrm{A}$ is considered in the first reaction. In the second reaction the affinity energy E cluster to the inert particles is considered. The clusters are assumed to be structurally completed, in which large A, little $\mathrm{E}$ and the difference Comp $=\mathrm{A}-\mathrm{E}$ attains the maximum or close to it. It should be noted that the respective energy parameters are considered with averaging all possible degrees of freedom - the geometric properties of the clusters, the position of adhered particles and similar values.

Elements of the structure of the material - crystals and colloids of the binder, particles of filler and additives, layers of free and bound water, internal interfaces, cracks and pores constitute the physical and geometric complexes, where connections in many cases are formed owing to adhesivecohesive interaction (adhesive microcontacts). Structures considered qualitatively with the above positions can be roughly divided into two classes - structurally completed and structurally incomplete [3]. Structurally incomplete clusters are subjected to transformation - they are either destroyed or complete the structure of particles coming from the binder dough (Fig.4). Structurally completed clusters influence the properties of materials differently and, in particular, can significantly degrade the strength characteristics.

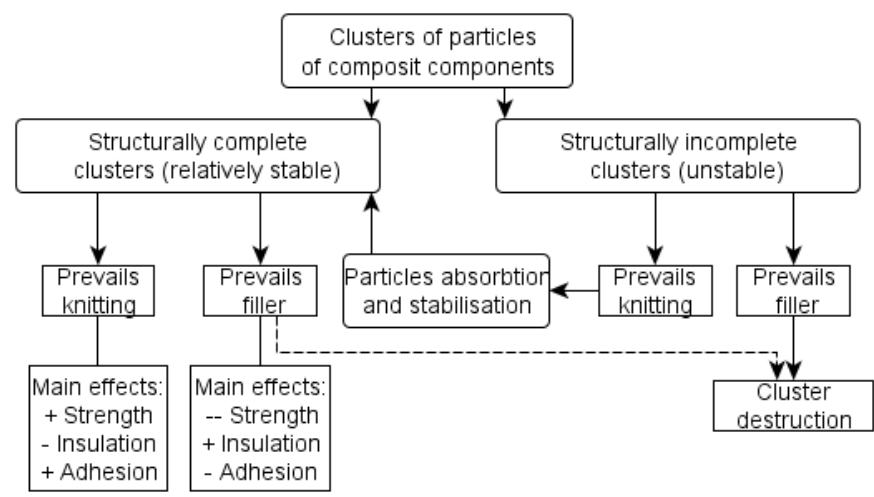

Fig.4. Classification of the clusters, the dynamics of their change and their impact on material properties.

Structurally completed cluster of inert filler particles formed around the binder particles is stable. One kind of optimal thermal conductivity and strength of cluster structures, especially effective in solid grains of filler, is alternating, wherein the conductive binder particles contact each other indirectly, through the filler (Fig.5).

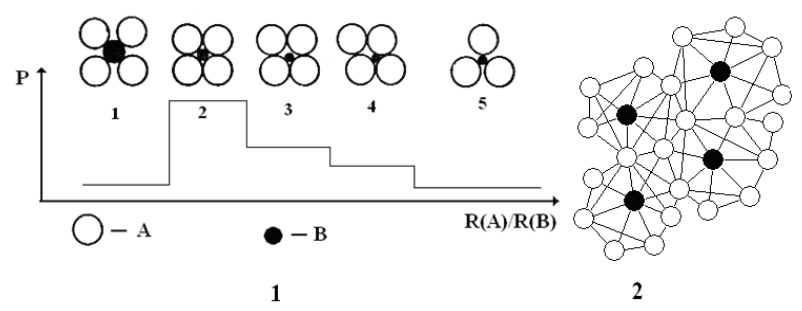

Fig. 5. The probability of formation of structurally completed (1, cluster 2$)$ and structurally incomplete clusters $(1$, cluster $1,3,4,5)$ and a variant of the elementary structure of the thermal protection material completed (2). A - filler particles; B - binder particles.

One approach to the problem of formation of structurally stable clusters, based on the rules of the Magnus-Goldschmidt and Pauling's theory of coordination polyhedra [4], is taken from crystallography. The main part of the relevant rules is purely geometrical and can be approximately applied to larger particles of heat-insulating fillers and binders. Table 1 summarizes the types of the main coordination polyhedra and their corresponding ratio of the radii of the particles. In the first column, we consider the case when the particles $\mathrm{A}$ are smaller, coordination of the particles B is happening around them. In the second, particles A are big, they are coordinated around B.

TABLE 1

\begin{tabular}{|c|c|c|c|}
\hline $\mathrm{R}(\mathrm{A}) / \mathrm{R}(\mathrm{B})$ & $\mathrm{R}(\mathrm{A}) / \mathrm{R}(\mathrm{B})$ & $\begin{array}{c}\text { Coordination } \\
\text { number }\end{array}$ & $\begin{array}{c}\text { Shape of the } \\
\text { environment }\end{array}$ \\
\hline $0-0.15$ & $6.45-\infty$ & 2 & Dumbbell \\
\hline $0.15-0.22$ & $4.45-6.45$ & 3 & Triangle \\
\hline $0.22-0.41$ & $2.41-4.45$ & 4 & Tetrahedron \\
\hline $0.41-0.73$ & $1.37-2.41$ & 6 & Octahedron \\
\hline $0.73-1.00$ & $1-1.37$ & 8 & Cube \\
\hline 1 & 1 & 12 & $\begin{array}{c}\text { Cuboctahedron } \\
(12 \text { vertices })\end{array}$ \\
\hline
\end{tabular}


When the ratio of the radii of the binder and filler particles is approaching the middle of the respective interval, incomplete clusters of low strength are forming. At the same time, if the structure-forming additives perform, in particular, disaggregating function, the corresponding values are favorable. Unless they are sealed, locally tetrahedral packing formed by several deformed tetrahedra is often formed. If in this case the radius of the most additive particles is $r$, the radius of the most particles of the binder should belong to the interval $0.22 \mathrm{r}-0.41 \mathrm{r}$, and the optimum structure is formed by $\approx 0.3 \mathrm{r}$.

Look at an example of the proposed methodology. The components of the mixture are gypsum $\Gamma-5$ as a binder and metakaolin as an additive, it positively influences the strength characteristics. From the distributions obtained by computer microscopy (Fig. 8) it is seen that gypsum particles are generally larger. The average particle size of gypsum -0.012 $\mathrm{mm}$ and of metakaolin $-0.004 \mathrm{~mm}$. Based on the data reviewed, it can be concluded that there is consistency in the distribution, and gypsum particles in the mixture of these two materials will be grouped around the particles of metakaolin of the most likely tetrahedron form.
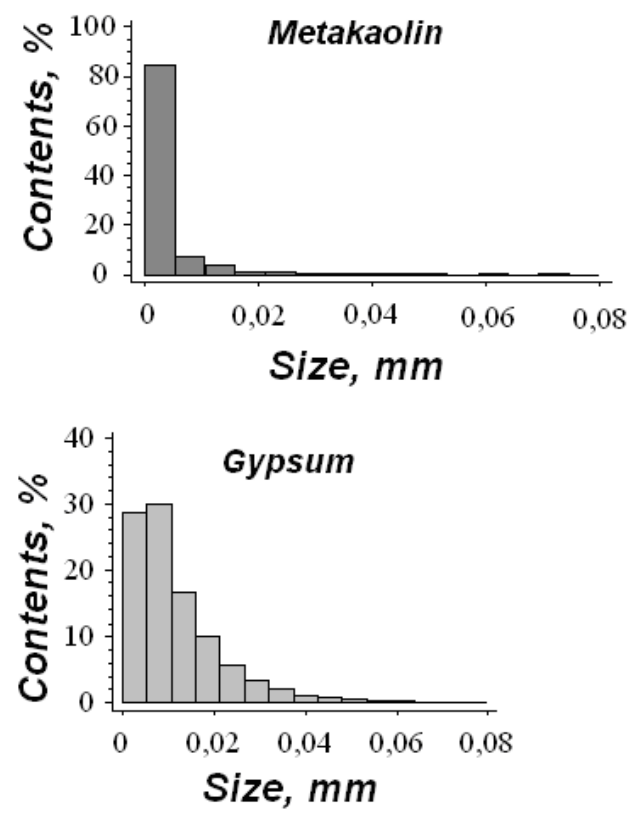

Fig. 6. Granulometric histogram of gypsum and metakaolin.

It turned out that in the transition from model media to the investigated plastering compositions with proportions of the components considered in the percolation theory and experimental investigations, material is easily destroyed. The main direction of increasing its strength is structural optimization, which was carried out from several perspectives: the study of the role of structure-forming particles to increase the strength based on the theoretical concepts discussed above and the choice of additives having appropriate particle size. It should be noted that the methods of structural optimization can improve the performance of, e.g., thermal conductivity $\lambda_{\text {mat }}$ only in a certain range around the main line defined by the density (corresponding to a proportion of binder in these materials) (Fig. 7).

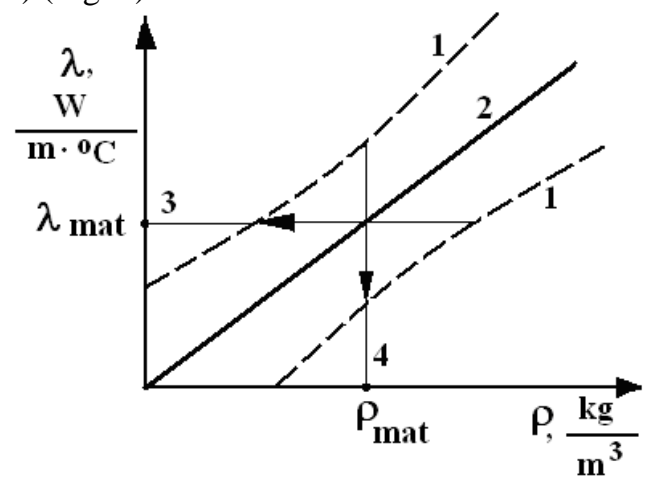

Fig. 7. The main tasks of structural optimization of the heat insulating composite: 1 - boundaries of structural optimization; 2 - main dependence of the thermal conductivity from the material density; 3.4 - Displaying two corresponding problems of structural optimization.

As far as the formation of structurally completed clusters equiprobably in relation to the types of particles, additional steps were taken to prevent the formation of structurally completed clusters of filler particles and additives with a small amount of binder or without binder at all. The method of structural influence on the composite mixture of this type, which leads to a decrease in the proportion of structurally complete filler clusters - the introduction of low concentrations of fine mineral additives, was experimentally found.

The introduced fine particles of these additives are pushing the filler particles, which promotes more complete hydration of the binder. Due to this effect, structural strength characteristics of the material are improved [5] (Fig. 8).
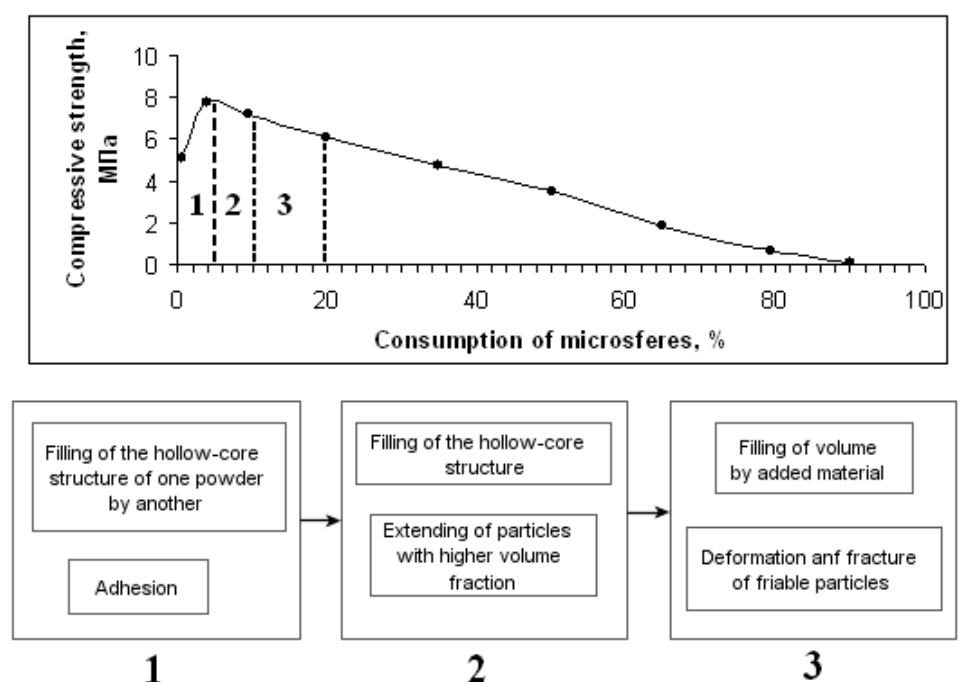

Fig. 8. Effect of additives on the strength of the mineral material: experimental dependence and conditions prevailing at introduction the mineral additives of various concentrations: 1- (0-5\%), 2- (5-10\%), 3-(10- 20\%).

For structural optimization of the composite mixture it turned out that the most useful is the beginning of the range $2(\sim 5 \%)$. Structurally incomplete filler clusters at this stage acquire the completeness and stability due to grain binder. 
The efficiency of mineral additive in these conditions was studied by volume metric analysis. It is based on the study of the volume of powder mixtures in relation to the initial volume of the mineral component. In the case of fine powders, a significant effect is caused by the electrostatic interactions, and the charges are induced particularly by friction. The total effect of these reasons leads to a significant deviation volume metric curve in the concentration, corresponding to the structural and mechanical hardening discussed above. Some results of nonadditivity for two-component mixtures are shown in Fig. 9.
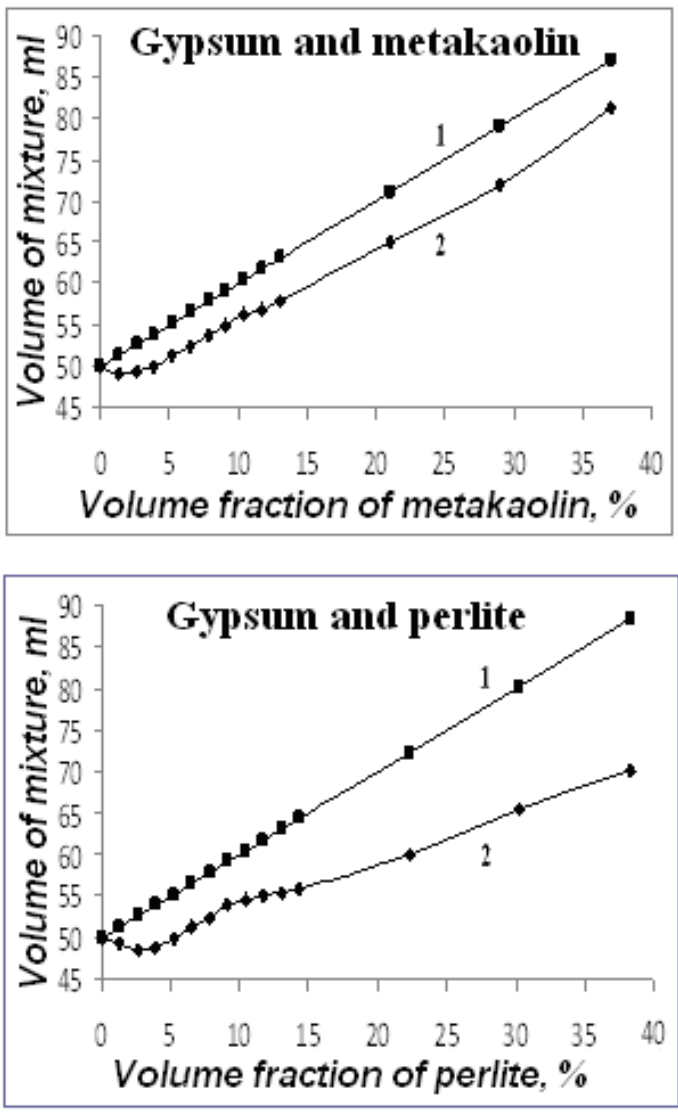

Fig. 9. Non-additivity of volumes of the powder mixtures.

The reviewed preliminary investigations and theoretical models allow considering qualitative composition of the material and transition to the planned experiment. Methodical bases of structural optimization are general and can be used for other tasks related to building materials.

\section{REFERENCES}

[1] B. I. Shklovsky, A. L. Efros, "Elektronnye svoystva legirovannykh poluprovodnikov", Chap. 5. M.: Nauka, 1979.

[2] Tarasevich Yu. Yu. "Perkolyatsiya: teoriya, prilozheniya, algoritmy" M.: Yeditorial URSS, 2002. - $112 \mathrm{p}$.

[3] V.Ya. Kersh ., A.V. Kolesnikov, D.V. Kersh "Izucheniye teplofizicheskikh svoystv mnogokomponenitnykh materialov metodom analogy" Visnik odeskoï derzhavnoï akademiï budivnitstva ta arkhitekturi, № 47, part1, 2012, pp. 129-134

[4] A.V. Kolesnikov, V.Ya. Kersh, D.V. Kersh, T.V. Lyashenko "Analiz strukturnykh vzaimodeystvy $\mathrm{v}$ materialakh i smesyakh obyemometricheskim metodom." Visnik odeskoï derzhavnoï akademiï budivnitstva ta arkhitekturi,№ 49, Odessa, 2014, pp.163-170.

[5] D.V. Kersh, A.V. Foshch, O.N. Marchuk "Oblegchenny gipsobeton dlya rekonstruktivnykh zadach v gorodskom stroitelstve" / . // Proceeding of MNPK «Energoyefektivni tekhnologï $v$ miskomu budivnitstvi ta gospodarstvi», ODABA, 2011, pp. 56-78 